\title{
Chile o una Loca Geografía
}

M I primera intención al leer esta obra de Benjamín Subercaseaux 11 fué escribir sobre ella un largo y serio estudio crítico. Después, esto me ha parecido una profanación. Este libro es como una pintura ante la cual toda palabra resulta vana y atrozmente profanadora; es un libro hecho de impresiones, construído sobre la sensibilidad y dirigido a la sensibilidad; analizarlo con el sentido común sería confesar de inmediato que no lo hemos captado.

Yo me figuro la actitud de los sabios ante la obra de Subercaseaux. "Erudición de segunda mano, es vago y ligero, irrespetuoso para la ciencia", dirán. Me imagino la reacción de los chilenos en general; es posible que se sientan avergonzados porque el libro es demasiado bello, y en nuestra querida patria se huye de lo verdaderamente bello así como de lo verdaderamente alegre. Yo sé que no es bueno decirlo, pero lo digo porque lo he observado tanto que sería hipocresía si me lo guardara. $Y$ además va a ser oportuno, porque ante la Laca geografía los chilenos se van a ruborizar y evadirán el juicio con un chiste hiriente. Parece que entre nosotros se prohiben las expresiones demasiado espontáneas $y$, ante el que se exalta demasiado, decimos que se "degrada". ¿Ante qué y en qué sentido? No lo sabemos; se "degrada", decimos, y lo combatimos con ironia.

El entusiasmo de Subercaseaux por su tierra es el de un niño que por centésima vez descubre el encanto de su juguete preferido. Es tan optimista, tan sano, tan santo, tan humano, que arrebata y contagia. En esta Geografía se aprende una palabra que es una canción: Chile; se aprende la estructura de tuna tierra que es un puzzle, un mar con piratas, pescadores y leyendas, islas misteriosas y cerradas como una sorpresa ante la curiosidad del hombre, selvas 
en las cuales dos hombres separados por escasos metros de maleza tardan dos días en encontrarse, montañas que se hunden y se levantan en el océano como en los dibujos animados; se lee casi la mitad del libro y no se sabe aún si en Chile los volcanes están en las cordilleras o en el fondo del mar; la verdad es que están en ambas partes: la chilena es la naturaleza más llena de sorpresas que hemos conocido. Es la naturaleza que uno imagina a los catorce años durante la soporífera clase de Geografía en el Liceo. Al menos yo la imaginaba; oyendo al calvo profesor hablar de archipiélagos, golfos, istmos, corrientes, etc., yo yeía todas estas cosas moverse con vida propia y acelerada; las veía cambiar de sitio en los mapas, girar como carrouseles, saltar o doblarse, alzarse y hundirse y hacer reverencias. Especial fantasía ponía yo en mover los jardines; nunca he concebido un jardín estático; sólo creo en los jardines con movimiento que hacen cien dibujos con masas de flores en el espacio de un minuto; arbustos que se transforman en fuentes, árboles que cambian de hoja, de fruto y de tronco, corrientes de perfumes mezclados con intención maligna. Para los niños que no pueden encadenar la imaginación, Subercaseaux ha producido su obra; es un estimulante $y$ un calmante a la vez; dice tanto como sugiere. Todos los milagros de la tierra son posibles después de leer este libro: los que conocemos, los que suponemos y los que vamos a conocer. Enseñar esta Geografía en el Liceo causaría una verdadera revolución. Yo creo que el inmediato resultado sería que los chilenos amarian de nuevo a Chile y se pondrían a vagar como locos de norte a sur del país.

Se desprende de esta obra una gran veneración por la tierra; es la veneración que es amor al mismo tiempo y, lo que es más notable, en ella está el amor primitivo del hombre que ama a su tierra sencillamente porque nació en ella y porque ella es para él como la piel que cubre su cuerpo, y también está el amor aprendido en la sublimación, el amor que resulta de un conocimiento, que es la recompensa después de una ardua investigación, y como cúspide de todo esto están los dos amores juntos: la visión del que ha salido lejos de la patria y después de mucho merodearla, sin acercársele mucho, ha conseguido descubrirla con la mirada de afuera, ha aprendido lo que la tierra vale en el concierto de las demás, lo que la tierra significa en su singularidad, es decir, ha captado "su mensaje". 
¿Cuántos van a decir que esta Geografía se lee como una novela? ¿ Sabrán ellos hasta quẻ punto tienen razón? Porque en verdad la Loca geografia tiene argumento y personajes y es tanto historia como ficción. El argumento empieza no sé cuántos miles de años atrás con el relato de probables visitas hechas a nuestro Continente por razas viejas de las cuales nos quedan probables vestigios. Continúa la trama con la historia de los pueblos indigenas que se disputaron nuéstra tierra como si hubiera sido una mujer. No voy a repetir los nombres de estos pueblos porque, en primer lugar, siempre me ha sido difícil recordarlos $y$, en segundo lugar, bueno, creo que basta con el primero. Pero los atacameños, los quichuas, los araucanos, tienen su parte en la intriga; de esto me hallo seguro. Un episodio interesante y misterioso to constituye el destino de los pascuenses, que parecen haber llegado a la isla como el humo y haberse quedado en ella convertidos en piedra. Los fueguinos son los niños que despiertan la piedad y nos ponen sentimentales; son como los niños de Dickens. La intriga prosigue su desarrollo y llegamos a la completa aparición de los "villanos": los conquistadores. No recuerdo si Subercaseaux los llama villanos en alguna parte de su libro, pero esto no tiene importancia porque sabemos que el novelista no necesita decir que tal personaje es un villano para que nos demos cuenta de que lo es; basta con que lo haga actuar. $\mathrm{Y}$ asi sucede aqui con los conquistadores. ; Oh! estos maestros de la traición y del garrotazo por la espalda; ellos huyen en los barcos cargados de viveres y abandonan a sus capitanes en la soledad de los mares a merced del hambre $\mathrm{y}$ de las tempestades, se apoderan del gobierno mientras el Gobernador combate a los indios, se escapan con el dinero, se calumnian, se asesinan, y todo con el respeto debido a Su Majestad y por la gloria del Reino. No sé por qué los norteamericanos no han tomado de modelo a algún Pizarro para sus películas de cozwboys: es un "villano" perfecto, es genial. Con los conquistadores se cumple el ingenuo concepto teatral de otras edades - y de las películas americanas precisamente - que nos ofrecía "villanos" totales, "villanos" villanos.

El argumento continúa por aquí y por allá, a veces un poco ahogado por la exuberancia del paisaje, como en las novelas de Mariano Latorre, quien, por lo demás, es uno de los personajes del libro, pues comete sus dos o tres buenas acciones que tienen 
relación con el héroe que, como diremos más adelante, es Chile. Mariano Latorre es un cazador de zorros en esta Loca geografía y un hombre que ha contado historias extraordinariamente verídicas sobre los huasos del Maule.

La trama se complica al llegar a la época moderna con ciertas emigraciones auspiciadas por otro de los personajes: Balmaceda, y conducidas hacia el sur por un típico ejemplar del héroe de libreta de notas bajo el brazo: Pérez Rosales. Estas inmigraciones iniciadas en buena hora, van a acarrear muy pronto su mala hora. Se complica también el asunto con la epopeya del norte - la fiebre del salitrey aun, corriendo el set hacia el centro, con la búsqueda del oro en minucia, más al sur con la búsqueda del oro negro y más al sur todavía, con la búsqueda del horizonte simplemente. Aquí la trama se hace apasionante $\mathrm{y}$ a veces trágica: desolación y miseria, injusticia, incomprensiones, errores, falta de visión, todo se combina para acentuar la intensidad del desenlace que se avecina. Cuando digo "aqui" me refiero tanto al norte como al centro y como al sur.

La intriga alcanza su cúspide en Santiago; la capital es más - o menos la vampiresa de la novela. Se lo traga todo; es inconsciente o irreflexiva, cruel con crueldad de niño; atormenta a las provincias, las engaña, las explota, las adula, las posee, sin devolver nada en cambio. Como personaje está maestramente trazado. Antes de leer a Subercaseaux no se sabe qué es Santiago; después de leerlo no se sabe tampoco, pero, en cambio - he aquí la maestría, he aquí el hallazgo-, se sabe que no se sabe lo que es Santiago. Y Santiago está captado. Porque esta ciudad es, como lo confiesa Subercaseaux, huidiza y extraña, extraordinariamente difícil de caracterizar, escapa a las interpretaciones, nunca ofrece su tipo. Santiago es quizá más compleja que el roto, y ya sabemos cuán complejo es el querido personaje; alli están como la mejor prueba los fracasos de media docena de notables escritores que han tratado de retratarlo. Es en esta cualidad de inaccesible, en su gesto huraño, en su no darse, en su ligero vivir cambiándose de trajes todos los días y, no obstante, permaneciendo en alguna parte inmutable, en alguna parte imposible de fijar -a menos que fuera en su mismo acto de cambiar, que es nuestra idea-; es aquí donde empieza a captarse el alma de Santiago. Poco deja la vampiresa al evaporarse en la Loca geografía; pasa con un apresuramiento cansado y no alcanza a posar; el cuadro es 
menos que una instantánea o, mejor dicho, es más que una instantánea, más sutili, más infinitamente sutil que una instantánea. $\mathrm{Y}$ allí está Santiago incuestionablemente.

Valparaíso es el amigo del héroe a quien ayuda y divierte $y$ encanta en la más ebria de lás inconsciencias. Uno no llega a comprender si este puerto está borracho de vino, de mar, de viento, de nostalgia, o simplemente borracho de cerros. Personalmente creo que los cerros hacen perder a Valparaíso su sentido del equilibrio $y$, por tanto, el sentido de su propio valor. Este puerto que aparece en las páginas de las más extraordinariamente raras novelas inglesas, chinas, escandinavas, americanas; que aparece nombrado en las canciones anónimas de cien pueblos y despierta en los niños de cuatro lạdos del mundo un paraíso de aventuras, este puerto se ignora a sí mismo; Chile lo ignora, lo ignoran los chilenos y alli vive, mojado y ebrio, con una pipa vieja entre los labios, botado entre cerros, mugriento y famoso.

La riqueza de argumento y personajes de la Loca geografía supera los alcances de una sinopsis. No sería posible detallar las figuras regionales que desfilan por estas páginas hábilmente descritas e interpretadas. Es, sí, necesario, destacar que en el total de ellas hay la figura de un héroe central, de un héroe que es sintesis de todos los elementos humanos y telúricos esparcidos por el libro; este héroe es Chile; surge de la Geografía en relieves intensos; es un personaje tipo. Su singularidad apasiona. Subercaseaux lo ha caracterizado con la mano ligera de un narrador de aventuras, a lo Stevenson, y con la mano calma y generosa de un hondo conocedor de almas. Chile está en este libro con su,presencia física y su contextura espiritual. Para quienes nos creen un pueblo sin personalidad propia, formado de diversos y dispersos materiales, un pueblo que se disgrega en la mediocridad, Subercaseaux ofrece una lección. El no canta una oda a Chile, no se pierde en exuberancia verbal: El nos da, como en las novelas de los maestros realistas, la figura destrozada; sufriente, amarga, de un pueblo que pasa a través de siglos por un destino de tragedia, pero que, quién sabe por qué milagrosa fuerza étnica, se mantiene homogéneo, unido y firme ante los ataques de la naturaleza, indestructible, mientras más golpeado más fuerte y que, aunque en verdad inactivo e indiferente, parece estar esperando un gran hecho, algo tremendo que lo. salve o lo aniquile para siempre. 
¿Qué significa este libro en la creación literaria de Subercaseaux? Yo me atrevo a decir que Subercaseaux está aquí en plena demostración de su valor personal. Hay en esta obra tal seguridad y fuerza de pensamiento, expresada de un modo tan sencillo y agradable, que no puede ser sino el resultado de la completa madurez del autor. Su estilo está tocado con la gracia que es peculiar a Subercaseaux y que ni siquiera ha vacilado al entrar en contacto con conocimientos exactos que son en gran parte la base de esta obra. El autor de Zoé, Contribución a la realidad, halla aquí el terreno justo para su tipo de interpretación. I a unidad del tema le da unidad a su pensamiento. No hay aquí ni rastro de divagación, nada que esté de sobra. Su biografia de Chile llega a una culminación; Subercaseaux ha entrado con imaginación, sensibilidad y sólido juicio por cuanta vena se manifiesta viva en nuestra tierra; con la rapidez de un viajero, pero con la pesada conciencia de quien se siente viajando por su propio destino; Subercaseaux expresa el mensaje de Chile con una veracidad que tendrá que hacer pensar al que tenga con que hacerlo.

Fernando Alegría, University of California. 